San Jose State University

SJSU ScholarWorks

Master's Theses

Master's Theses and Graduate Research

1993

\title{
The difference in perceived self-efficacy scores between elderly arthritis sufferers who exercise and those who do not exercise
}

Elbina Batala Rafizadeh

San Jose State University

Follow this and additional works at: https://scholarworks.sjsu.edu/etd_theses

\section{Recommended Citation}

Rafizadeh, Elbina Batala, "The difference in perceived self-efficacy scores between elderly arthritis sufferers who exercise and those who do not exercise" (1993). Master's Theses. 641.

DOI: https://doi.org/10.31979/etd.7tj9-6hcy

https://scholarworks.sjsu.edu/etd_theses/641

This Thesis is brought to you for free and open access by the Master's Theses and Graduate Research at SJSU ScholarWorks. It has been accepted for inclusion in Master's Theses by an authorized administrator of SJSU ScholarWorks. For more information, please contact scholarworks@sjsu.edu. 


\section{INFORMATION TO USERS}

This manuscript has been reproduced from the microfilm master. UMI films the text directly from the original or copy submitted. Thus, some thesis and dissertation copies are in typewriter face, while others may be from any type of computer printer.

The quality of this reproduction is dependent upon the quality of the copy submitted. Broken or indistinct print, colored or poor quality illustrations and photographs, print bleedthrough, substandard margins, and improper alignment can adversely affect reproduction.

In the unlikely event that the author did not send UMI a complete manuscript and there are missing pages, these will be noted. Also, if unauthorized copyright material had to be removed, a note will indicate the deletion.

Oversize materials (e.g., maps, drawings, charts) are reproduced by sectioning the original, beginning at the upper left-hand corner and continuing from left to right in equal sections with small overlaps. Each original is also photographed in one exposure and is included in reduced form at the back of the book.

Photographs included in the original manuscript have been reproduced xerographically in this copy. Higher quality 6" $\mathrm{x} 9$ " black and white photographic prints are available for any photographs or illustrations appearing in this copy for an additional charge. Contact UMI directly to order.

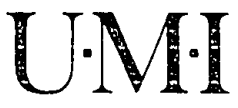

University Microfilms Internatıonal

A Bell \& Howetl Information Company

300 North Zeeb Road. Ann Arbor, MI 48106-1346 USA

313: $761-4700 \quad 800: 521-0600$ 
Order Number 1354156

The difference in perceived self-efficacy scores between elderly arthritis sufferers who exercise and those who do not exercise

Rafizadeh, Elbina Batala, M.S.

San Jose State University, 1993

Copyright $@ 1993$ by Rafizadeh, Elbina Batala. All rights reserved.

$\mathrm{U} \cdot \mathrm{M} \cdot \mathrm{I}$

300 N. Zeeb Rd.

Ann Arbor, MI 48106 


\title{
THE DIFFERENCE IN PERCEIVED SELF-EFFICACY SCORES BETWEEN ELDERLY ARTHRITIS SUFFERERS WHO \\ EXERCISE AND THOSE WHO DO NOT EXERCISE
}

\author{
A Thesis \\ Presented to \\ The Faculty of the Department of Nursing \\ San Jose State University \\ In Partial Fulfillment \\ of the Requirements for the Degree \\ Master of Science
}

by

Elbina Batala Rafizadeh

August, 1993 


\section{APPROVED FOR THE DEPARTMENT OF NURSING}

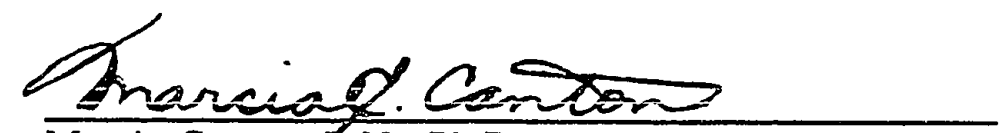

Marcia Canton, R.N., Ph.D.

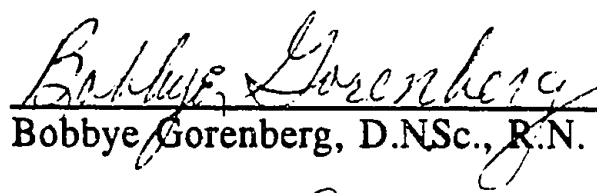

$\frac{\text { Thaila Gamamizm. M.D. }}{\text { Thaila Ramanujan, M.D. ( }}$

APPROVED FOR THE UNIVERSITY

M. Tou Oewandounck 


\begin{abstract}
THE DIFFERENCE IN PERCEIVED SELF-EFFICACY SCORES BETWEEN ELDERLY INDIVIDUALS WITH ARTHRITIS WHO EXERCİSE AND ELDERLY INDIVIDUALS WITH ARTHRITIS WHO DO NOT EXERCISE

By Elbina Batala Rafizadeh

An exploratory study was done to identify the difference in perceived self-efficacy scores among a convenience sample of 6 elderly individuals with arthritis who exercised and 6 elderly individuals with arthritis who did not exercise. It was predicted that participants who exercised would have a higher perceived selfefficacy score, the study found no difference between those who exercised and those who did not exercise. Investigation of the results showed that all participants exhibited self-efficacy by engaging in a regular social activity away from home and participants who exercised or did not exercise exhibited similar arthritic complications. This study indicates the need for further research to identify other variables, such as comparing individuals with arthritis who socialize and those who prefer to stay home, the role of attitude, or other pain management modalities.
\end{abstract}




\section{ACKNOWLEDGEMENTS}

In memory of Nader, the source of my inspiration. A very special thanks to Omeed, my son, and my parents, Michael and Tessie, for their support and understanding. Also, thank you to John, for his patience and support. A special thanks to Sharon Wahl, Marcia Canton, Bobbye Gorenberg, for their guidance in assisting me to complete this study. A special note to Steven Aquino for his assistance. 


\section{TABLE OF CONTENTS}

Page

LIST OF TABLES $\ldots \ldots \ldots \ldots \ldots \ldots \ldots \ldots \ldots \ldots$ vii Chapter

1. INTRODUCTION $\ldots \ldots \ldots \ldots \ldots \ldots \ldots \ldots \ldots$

Problem $\ldots \ldots \ldots \ldots \ldots \ldots \ldots \ldots \ldots$

Purpose and Need ................. 4

Research Questions ............... 5

Definition of Terms $\ldots \ldots \ldots \ldots \ldots \ldots \ldots$

Summary $\ldots \ldots \ldots \ldots \ldots \ldots \ldots \ldots \ldots \ldots$

2. CONCEPTUAL FRAMEWORK AND

REVIEW OF LITERATURE $\ldots \ldots \ldots \ldots \ldots \ldots .8$

Conceptual Framework $\ldots \ldots \ldots \ldots \ldots \ldots \ldots$

Concept of Perceived Self-Efficacy $\ldots \ldots \ldots \ldots \ldots \quad 8$

Orem's Self-Care Theory of Nursing . . . . . . . 11

Review of the Literature $\ldots \ldots \ldots \ldots \ldots \ldots \ldots \ldots$

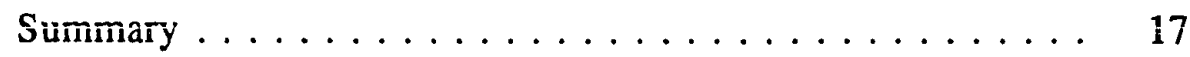

3. METHODOLOGY $\ldots \ldots \ldots \ldots \ldots \ldots \ldots \ldots \ldots$

Research Design ................... 18

Subjects $\ldots \ldots \ldots \ldots \ldots \ldots \ldots \ldots \ldots \ldots \ldots$

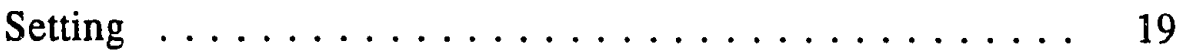

Data Collection .................... 19

Description of Assessment Tool ............ 21

Analysis Procedures . . . . . . . . . . . . . 22 
4. ANALYSIS AND INTERPRETATION OF DATA . . . . . 23

Analysis of the Data ................... 23

Demographic Profile ... . . . . . . . . . . . . 24

Interpretation of Findings . . . . . . . . . . 27

5. DISCUSSION AND CONCLUSION $\ldots \ldots \ldots 28$

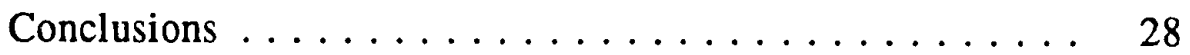

Scope and Limitations .................. 30

Recommendations ................... 32

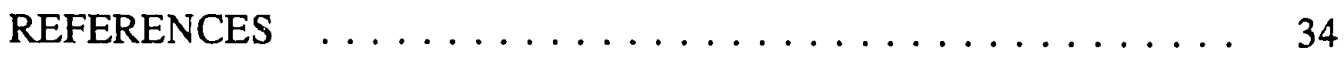

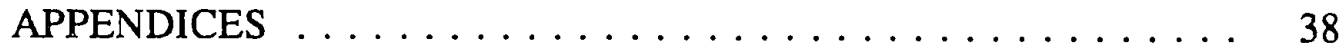

Appendix A: Human Subjects Approval Letter ........ 38

Appendix B: Participation Consent Form . . . . . . . . 40

Appendix C: Authorization to Use Questionnaire . . . . 43

Appendix D: Agency Consent Letters .......... . 45

Appendix E: Demographic Face Sheet . . . . . . . . 49

Appendix F: Arthritis Self-Efficacy Scale .......... 51

Appendix G: Raw Data Scale ............. 56 


\section{LIST OF TABLES}

Table Page

1. Mean Age and Gender of Participants by Exercise Group . . . 24

2. Analysis of Perceived Self-Efficacy of

Exercisers and Nonexercisers . . . . . . . . . . . 26

vii 
Chapter 1

INTRODUCTION

It is estimated by the Arthritis Foundation that there are over 37 million Americans diagnosed with arthritis (Pisetsky \& Trien, 1991). Arthritis is not specific to any age group, but usually starts in middle age and can begin in childhood (Lorig \& Fries, 1986). Among the elderly, half of the people over 65 are afflicted with arthritis (McIlwain, Silverfield, Burnette, \& Bruce, 1991). The Harvard Health Letter (Liang, 1992) documents that $80 \%$ of people over 65 have osteoarthritis. According to Stefl (1984), statistics revealed that arthritis was the most prevalent health complication among the elderly, ranking at 38\%; hearing impairments ranked at 29\%; and vision impairment, hypertension, and heart conditions, ranked at $20 \%$ each. Because of the widespread prevalence of arthritis, it is important that health care workers and those afflicted with arthritis have a good understanding of the disease to promote active participation in treatment modalities.

Arthritis is a degenerative disease characterized by inflammation in or around the joint (Mcllwain et al., 1991). There are over 100 types of arthritis, of which the two most common are rheumatoid and osteoarthritis (Pisetsky \& Trien, 1991). These disorders, which also include systemic lupus erythematosus, scleroderma, ankylosing spondylitis, gout, and bursitis, are collectively called "rheumatic disorders." They are defined as disorders which "produce pain and stiffness in some portion of the musculoskeletal system ... [and] primarily affect the joints and 
surrounding connective tissues" (Price \& Wilson, 1986, p. 962). According to McIlwain et al. (1991), categorization of arthritis is simplified into two basic types: osteoarthritis and inflammatory (rheumatoid) arthritis. Osteoarthritis is defined as a degenerative disorder, usually resulting from the "wear and tear" of the joints. Signs and symptoms associated with osteoarthritis include joint pain, which is characterized by a slow progression and intermittent occurrence (Abrams \& Berkow, 1990). Osteoarthritis is nonspecific to age but is more common among older people.

Inflammatory types of arthritis refer to inflammation of the linings of the joints, the most common being rheumatoid arthritis (Mcllwain et al., 1991). Rheumatoid arthritis is more common in women than men and can occur at any age (Marino \& McDonald, 1991). Juvenile rheumatoid arthritis occurs in children but is usually outgrown by adulthood (Pisetsky \& Trien, 1991). Signs and symptoms associated with rheumatoid arthritis include fatigue, pain or joint tenderness, difficulty in joint movement, redness and warmth of a joint, and unexplained weight loss, fever, or weakness associated with joint pain (Pisetsky \& Trien, 1991). Physical discomfort from arthritis results in complications in daily living, such as difficulty dressing, cooking, and housekeeping. Individuals who experience arthritis discomfort may choose to become less mobile to avoid the pain, which can then further decrease the flexibility of the affected joint (Mcǐlwain et al., 1991).

Much research has been directed toward the management of arthritic discomfort, and recommendations include a combination of proper 
nutrition, exercise, medication, and rest (Mcllwain et al., 1991). The Stanford Arthritis Center has developed an arthritis pain management program known as the Arthritis Self-Help Program (Lorig \& Fries, 1986). The program is designed to teach people with arthritis how to manage their pain and discomfort. The program is goal oriented and each person is responsible for the completion of his/her goals. For example, goals could include completion of a daily exercise routine, diet maintenance to reduce weight, or a daily scheduled stress-reducing exercise. Successful pain management requires individual persistence, determination, and motivation to overcome the problem (Lorig \& Fries, 1986).

Self-efficacy is defined as individuals' belief in their ability to perform necessary behaviors (Prkachin \& Cameron, 1990). An individual's perception of his/her self-efficacy is referred to as perceived self-efficacy. Self-efficacy is taught in therapeutic programs designed to assist individuals to develop coping patterns through the process of goal setting. For example, an individual may set a goal to complete a series of specific daily exercise activities designed to improve joint mobility and to increase tolerance of physical discomfort (Prkachin \& Cameron, 1990). Selfefficacy has been used in group therapy to assist people who suffer from chronic discomfort associated with disease (Herman \& Baptiste, 1990). According to Tunks (1990), self-efficacy used in therapy resulted in an improved coping behavior in the management of complications associated with chronic disease. 
Problem

According to Violon (1990), chronic discomfort or pain is usually seen as a symptom of disease; however, when afflicted individuals experience the continual presence of this pain, it may become a disease in itself. She suggests that older people who have been unable to successfully cope with the chronic discomfort and complications of arthritis may manifest behaviors, such as anxiety, depression, guilt, resentment, or ego disruption.

The focus of therapy should be to assist individuals to realize the effects of a coping behavior whicin has been successful in the management of chronic pain and discomfort. In other words, individuals can choose to cope with their complications by performing specific activities (such as exercise) designed to lessen the discomfort associated with arthritis, or they can succumb to the arthritic discomfort and choose not to perform activities because they are "too painful." This "non action" can result in further deterioration and immobility of the affected joints.

Self-efficacy has beeñ used in behavioral modification (Fordyce, 1978), group therapy (Lesage, Slimmer, Lopez, \& Ellen, 1989), and class settings which focus on techniques to manage discomfort due to arthritic complications (Lorig \& Fries, 1986).

\section{Purpose and Need}

The purpose of this study was to determine if perceived sclf efficacy was higher among elderly individuals with arthritis who exercised regularly than among elderly individuals with arthritis who did not exercise regularly. As mentioned, arthritis is prevalent among older 
people, affecting their functioning level which can, in turn, lead to the ultimate loss of independence and autonomy. Elderly individuals who were once active in their communities may find themselves homebound and isolated. These elderly individuals may become inhibited from participating in any kind of activity due to the pain and discomfort associated with arthritis. It stands to reason that therapy which enhances improved coping behavior regarding the management of arthritis can have long term benefits for these individuals.

Care of the elderly is often dependent upon the nurse, whether in a skilled nursing home, a board and care facility, or in a home setting. Arthritic discomfort affects an individual's ability to perform the normal activities of daily living. This may result in a depressed, anxious, homebound elderly person and lead to decreased joint mobility as a result of disuse. The widespread prevalence of chronic arthritic ailments among the elderly (Lorig \& Fries, 1986) reinforces the need to identify helpful strategies which can be used by health practitioners who administer therapeutic interventions (e.g., exercise classes and stiress and relaxation programs) designed to assist elderly people in coping with arthritic complications.

Research Questions

The study posed the following questions: (a) "Is there a difference in perceived self-efficacy scores between elderly individuals with arthritis who participate in regular exercise activity and those elderly individuals with arthritis who do not participate in a regular exercise activity?" and (b) "What is the demograpnic profile of the two groups?" 


\section{Definition of Terms}

For the purposes of this study, the following definitions apply:

1. Perceived self-efficacy is "an individual's judgment of how well one can execute courses of action required to deal with prospective situations" (Bandura, 1982, p. 122).

2. Learned helplessness refers to the personal attributes having characteristics of passivity and dependence; these attributes occur with depression and loss of control (Lesage et al., 1989).

3. Arthritis is inflammation of the joints which includes over 100 varieties, the most common of which are rheumatoid arthritis and osteoarthritis (Lorig \& Fries, 1986).

a. Rheumatoid arthritis is a chronic atrophic disease, usually involving the connective tissues with a predilection of the small joints, especially the fingers (Lorig \& Fries, 1986).

b. Osteoarthritis is a degenerative joint disease characterized by degeneration of articular cartilage and hypertrophy of the bone, accompanied by pain with activity which subsides with rest (Lorig \& Fries, 1986).

\section{Summary}

Chronic complications of arthritis are common among the elderly, and there is no known cure for arthritis (Lorig \& Fries, 1986). The longterm effects of pain can result in decreased mobility and increased dependence on caregivers. Therapeutic interventions in various forms, such as medications, surgery, exercise, alternative therapeutic methods (e.g., acupuncture, chiropractic procedures), and exercise, are all options 
which can provide some relief from chronic arthritis pain. This study identified the role of perceived self-efficacy among elderly individuals with arthritis who exercised and elderly individuals with arthritis who did not exercise. The value of self-efficacy in therapeutic interventions can be significant because it can play a role in promoting elderly individuals to continue living independently at home. 
Chapter 2

CONCEPTUAL FRAMEWORK

\section{AND REVIEW OF RELATED LITERATURE}

Perceived self-efficacy has been incorporated into the development of therapeutic modalities which assist individuals suffering from chronic arthritis complications. Nurses are involved in assisting elderly people to cope with the pain and discomfort that accompany arthritis. The concept of self-efficacy is highly appropriate within the context of nursing practice. Self-efficacy and how it can be used in nursing practice comprised the conceptual framework for this study.

\section{Conceptual Framework}

\section{Concept of Perceived Self-Efficacy}

Bandura (1982) describes perceived self-efficacy as self-percepts of thought patterns, actions, and emotional arousal, which, in turn, affect one's coping behavior and sense of personal ability to maintain control of one's life. A study by Bandura and Schunk (1981) revealed that people who have a high sense of perceived self-efficacy exert more energy to meet the demands of a difficult situation. Beck (1976) notes that those who are less efficacious often dwell on personal inabilities and are consumed by the difficulty of the situation, thus creating more stress and promoting a potential for performance failure. Stressful situations divert attention from how to manage the complication, to concerns about the potential mishaps and failure (Bandura, 1982).

Bandura (1982) conceptualizes that perceived self-efficacy is based 
upon four principal sources: (a) vicarious experiences through observation of the performance by others; (b) verbal persuasion and social influences by others; (c) physiological states from which one judges his/her capability, strength, and endurance; and (d) individual success or failure of a particular performance.

Vicarious experiences refer to the observation of others performing the task at hand (Bandura, 1982). If others are observed successfully performing a task that one has not previously had the confidence to carry out, judgment regarding one's personal ability can be measurably altered. It is emphasized that when a person observes others succeeding, the confidence level to perform a task tends to increase.

Verbal persuasion has also been used to influence an individual's belief in his/her capability to achieve a goal. Human behavior is influenced through suggestion that a previously difficult task can be accomplished.

An individual's physiological state also influences beliefs about succeeding. Visceral arousal, tenseness, and stress often deter a persoñ's belief in personal ability or capability. Visceral agitation is stressful and characteristic of vulnerability and dysfunction (Bandura, 1982).

Individual successes or failures are referred to as "performance attainments," or the ability to successfully attain a certain skill or overcome a specific difficulty. This is also referred to as "enactive attainments" (Bandura, 1982, p. 126).

Bandura (1982) tested individuals who experienced phobias. Each of the four modes of influence-vicarious experience through observation, 
verbal persuasion, physiological states, and enactive attainments-was utilized to train each individual to overcome a phobia. Interestingly, the results revealed that enactive attainments (i.e., repeated individual successes) produced the highest and strongest coping efficacies.

Perceived self-efficacy has been useful in the therapeutic interventions for elderly individuals who have developed a psychosocial concept known as "learned helplessness" (Bandura, 1982). A study by Lesage et al. (1989) with elderly people living in a nursing home, showed that when individuals are confronted with uncontrollable events, they experience depression and loss of control, and develop personal attributes of passivity and dependence, or learned helplessness. Learned helplessness is defined as having personal attributes of passivity and dependence, which may occur with the presence of depression and feelings of loss of control. Thus, if an individual perceives that the pain of arthritis is beyond his or her control, the attributes characteristic of learned helplessness may eventually become manifest.

Seif-efficacy is the framework for the Stanford Arthritis Pain Management Course (Lorig, Chastain, Ung, Shoor, \& Holman, 1989, p. 38) which is based on the following assumptions:

1. Perceived self-efficacy for behaviors that affect improved health status is determined by an individual's belief that the result of the behavior will be an improved health status;

2. Perceived self-efficacy is dynamic and has potential for change;

3. Improved health status, because of a specific behavior, enhances perceived self-efficacy. 


\section{Orem's Self-Care Theory of Nursing}

Orem's (1991) theory of nursing is based on an individual's ability to maintain daily personal care. This care can be influenced by the state of health, environmental conditions, condition of the medical care received, or any other factor which may contribute to the individual's ability or inability to care for self. This conceptual theory of nursing is referred to as the self-care deficit theory of nursing which Orem describes as "the relationship between the action capabilities of individuals and their demands for self-care or the care demands of children or adults who are their dependents" (p. 73). Orem explains that nurses respond to human incapacities because of health deficiencies experienced by the care recipient.

"Self-care" is a central component in Orem's theory and is defined as the ability to care for one's self or one's dependents when ability is limited due to the state of one's health. A deficit occurs between the action that is required to maintain one's self-care and the capabilities of the individual. The therapeutic self-care demand is the care required to fulfill the requisites for human functioning. The nursing component, known as the nursing agency, attempts to fulfill this requisite through the practice of nursing.

Self-efficacy can be used by nurses when teaching others how to successfully cope with chronic disease. When a person is suffering from a health problem secondary to a chronic disease (e.g., arthritis pain, fatigue, or functional immobility), this person is experiencing a deficit to care for his/herself. The nurse's role, usually in the form of therapeutic 
intervention (e.g., teaching of pain management techniques, direct provision of comfort measures, or conducting a health-oriented class), can also include teaching the importance of self-efficacy to successfully cope with health problems due to chronic disease.

Review of Literature

As previously noted, perceived self-efficacy is incorporated in the Stanford Arthritis Pain Management course which has been used successfully for the past 10 years (Lorig \& Holman, 1989). A study of 190 people who initially took the course revealed that there was a lowered pain experience because, in addition to an improved baseline knowledge of arthritis, the people learned the importance of regular exercise and relaxation regimens (Lorig \& Holman, 1989). The Stanford Arthritis Center conducted arthritis self-management classes which were taught by individuals with arthritis or other persons who had an interest in arthritis. Lorig \& Fries (1986) noted that three concepts were emphasized in class:

1. Each person with arthritis is different. There is no one treaitment that is right for everyone.

2. There are a number of things people can do to feel better. These things will not cure most kinds of arthritis, but they will help to relive pain, maintain or increase mobility, and prevent deformity.

3. With knowledge, each individual is the best judge of which self-management techniques are best for him or her. (p. xvi) Lorig \& Fries (1986, p. 29) emphasize that each individual must take responsibility to manage his or her pain and then become an "arthritis self- 
manager." The class attempts to help the individual develop a higher sense of perceived self-efficacy for the purpose of effective arthritis pain management.

A study by Prkachin and Cameron (1990) pertaining to therapeutic interventions that modify behavior and cognitive functioning reveals that behavior which desensitizes fear and reinforces regular exercise and daily activity decreases the pain experience and improves pain tolerance. The individual is encouraged to set goals which would structure daily behavior patterns, improve joint mobility, and improve tolerance to cope with physical discomforts.

Herman and Baptiste (1990) state that cognitive behavior therapy interventions focus on changing an individual's attitude of learned helplessness to learned well behaviors. It has been found that learned helplessness is often associated with chronic pain. The behaviors of people who exhibit learned helplessness often elicit responses from significant others which, in turn, reinforce the learned helplessness (Fordyce, 1978). It is noted by Pearce and Tunks (1990) that those who have experienced failures often adopt helpless behaviors. The focus of rehabilitation for these individuals is to promote a sense of achievement and efficacy.

The role of perceived self-efficacy has been expanded to formulate new definitions of coping behavior. A recent study conducted by Smith, Dobbins, and Wallston (1991) of individuals afflicted with rheumatoid arthritis (mean age 54) found that psychological adjustment to the discomforts of the disease varied among individuals. The authors used the 
idea of perceived self-efficacy to develop a new concept called "perceived competence." Perceived competence is related to perceived self-efficacy but is different in that self-efficacy is behavior specific, while competence indicates one's general belief about his/her ability to interact productively with the environment.

Another study related to self-efficacy (Minor, Hewett, Webel, Anderson, \& Kay, 1989) showed a significant difference in exercise endurance, grip strength, and flexibility among individuals with rheumatoid arthritis and osteoarthritis who performed regular physical and conditioning exercises. The study involved 120 patients with rheumatoid arthritis or osteoarthritis who were placed in three exercise groups: (a) aerobic walking, (b) aquatic aerobics, and (c) nonaerobic range of motion. Subjects were evaluated after 12 weeks, 3 months, and 9 months of activity participation. The study revealed that the aquatics and walking groups showed a significant improvement in aerobic endurance, 50-foot walking time, mood, and physical activity in comparison to the nonaerobic group after the 12 week follow up and were able to maintain this level of functioning at the 3 month, 9 month, and 1 year follow up. It was noted that these findings support previous assertions that people with arthritis can achieve fitness and general well-being through regular exercise. The authors point out that exercise must be maintained on a regular schedule to improve fitness.

Perceived self-efficacy has been studied for its effects in the management of complications of rheumatoid arthritis through cognitivebehavioral treatment (O'Leary, Shoor, Lorig, and Holman, 1988). A group 
of 33 patients (mean age of 49.3 with a duration of rheumatoid arthritis ranging from 1 to 29 years) were divided into two subgroups-an experimental and a control group. The experimental group received cognitive behavioral treatment which consisted of 2-hour sessions for 5 weeks. This treatment included education and discussion of a biopsychosocial model of pain, training in several cognitive and behavioral pain-management strategies, and goal setting. Strategies to control the pain included relaxation, guided imagery, dissociation, relabeling, and selfencouragement. The control group participants received copies of The Arthritis Helpbook (Lorig \& Fries, 1986) which contains information pertaining to the Stanford Arthritis Center self-management course. The results showed improved self-efficacy scores, improved pain management abilities, and improved coping abilities in reference to depression and stress for the experimental group. The control group, however, did not show a significant decrease in pain levels and activity tolerance, nor did the control group show improved coping abilities or increased perceived self-efficacy scores. The study pointed out the therapeutic importance of utilizing self-efficacy in cognitive behavior therapy for managing the complications of rheumatoid arthritis.

Though previous studies have shown the positive associations between behavior modification and lowered arthritis discomforts, other studies concluded otherwise. A study by Lorig, Seleznick, Lubeck, Ung, Chastain, and Holman (1989) of 707 people with arthritis revealed a weak association between health behavior modification and health outcomes. Respondents were divided into two groups-a control group that received 
no intervention, and an experimental group that attended the 6-week Arthritis Self-Management Course. Despite successful results of past studies of people who took the course, this study indicated there was only a weak association between health behavior modification and respondents' individual perceptions of pain, disability, and depression.

Another study by Lenker, Lorig, and Gallagher (1989) of 54 people with arthritis who took the Arthritis Self-Management Course, likewise indicated no association between improved health behaviors (exercise, relaxation, walking) and health outcomes (levels of disability, number of visits to a physician). However, after further analysis, it was noted that the people who had experienced a positive outcome (lowered pain and disability, fewer physician visits) indicated that they perceived a sense of self-control over their disease; and the people who experienced a negative outcome (increased pain, disability, physician visits) perceived less control over the disease and had a negative emotional state.

A study which was conducted by Schiaffino, Revenson, and Gibofsky (1991) examined the role of self-efficacy beliefs on problemsolving capabilities, functional disability, and psychological well-being for 101 adult patients with rheumatoid arthritis. The study hypothesized that self-efficacy beliefs would be associated with better adjustment (lower levels of depression and disability) when assessed concurrently with the ability to cope and problem-solve, all independent of pain level. The results indicated that self-efficacy beliefs were associated only with improved functional ability. 


\section{Summary}

Perceived self-efficacy is currently being utilized in therapy to assist people with disabling phobias (Bandura, 1986), to assist the elderly to gain control of their lives, for alleviation of headache pain, and to promote recovery in cardiac patients (McLeod, 1986). Self-efficacy has shown its value when used in therapeutic interventions which assist people to cope with health problems associated with arthritis (Bandura, 1982; Lorig \& Fries, 1986; O'Leary et al., 1988; Pearce \& Tunks, 1990; Prkachin \& Cameron, 1990). The varied results from studies performed by Lorig, Seleznick, Lubeck, Ung, Chastain, and Holman (1989), Lenker et al. (1989), and Schiaffino et al. (1991) indicate the need for further research to investigate variables which may affect the goals of therapeutic interventions.

A nurse's role, according to Orem (1991), is to assist individuals experiencing health care deficits to regain optimal functioning capacity. The nurse could achieve this goal with elderly persons with self-care deficits secondary to arthritis discomfort by incorporating methods to improve perceived self-efficacy into exercise programs, arthritis selfmanagement classes, and individual counseling. 


\section{Chapter 3}

\section{METHODOLOGY}

\section{Research Design}

The study design was an exploratory survey which compared perceived self-efficacy scores between elderly individuals with arthritis who exercised and elderly individuals with arthritis who did not engage in a regular exercise activity. It was anticipated that elderly individuals who had higher perceived self-efficacy scores would be confident to manage their pain, perform specific tasks, and manage the complications of their arthritis. The design did not utilize a control group nor did it manipulate a dependent variable.

\section{Subjects}

The subjects consisted of a convenience sample of 12 older individuals recruited from three sites in northern California-two senior centers and an aquatics exercise class. Participants were required to be 65 years of age or older. Of the 12 participants, 6 were from one of the senior centers, 4 from the other senior center, and 2 were from the aquatics exercise class. Of the 16 people who had initially volunteered to participate in the study, 12 returned the questionnaires -3 from the aquatic exercise program and 9 from the other two senior centers. Respondents were over 65 years of age and were capable of reading and writing English. All participants were required to have had a diagnosis of arthritis for at least 1 year and had experienced at least one of the complications of arthritis listed on the demographic face sheet which was attached to the 
questionnaire (Appendix E). All participants were regular attendants of the senior centers and/or the aquatics exercise class. Of the 12 participants, 3 attended an exercise class, 3 exercised independently, and 6 engaged in no regular exercise routine to relieve arthritic symptoms.

The two senior centers and a physical therapy facility were located in both rural and urban areas of coastal northern California. Both senior centers were highly attended and offered an exercise program. Each senior center also served as a nutrition site offering lunch. One senior center site was located in a facility which also offered a day care for children, an arts center, and rooms available for classes and community activities. The other site served exclusively as a senior center. Each senior center site held exercise classes on specific days of the week; one site held classes on Mondays, Wednesdays, and Fridays; the other site held classes on Fridays only. The senior center site directors confirmed that the exercise programs were designed to assist the participants in improving joint mobility. The exercise programs were nonimpact, i.e., exercise activity was performed while the individual was seated. The aquatics exercise class for people with arthritis was located in a physical therapy facility, but participation was voluntary rather than having been prescribed by a physician. All of the exercise instructors were certified activity coordinators and had experience working with seniors.

\section{Data Collection}

All people attending the two senior centers on one day in December, as well as those attending the aquatics class one day in January, were invited to participate in the study on a voluntary basis. The purpose of 
the study and the procedure for completing the questionnaire and signing the consent form were explained. The questionnaires were then distributed to those who had agreed to participate. Participants who did not attend any of the exercise classes were asked, "Do you perform a regular exercise at home to relieve your arthritis discomforts?" The respondents" "yes" or "no" answers were written on the top right hand corner of the demographic face sheet. Each questionnaire was given a site number and a participant number. The site number was the last number of the site's street address (for example, if the street address was 513, the site number would be 3 ). The participant number followed a sequence, i.e., the first being 1 , the second 2 , and so on. This number was also written on the consent form that each person was requested to read and sign before participation in the study. This process identified each questionnaire by a number known only to the researcher, to assure anonymity.

Of the 16 people who initially volunteered, only 12 returned the questionnaire. Of those, 10 of the volunteers were from senior centers, and 2 were from the aquatics exercise class. None of the participants wanted to complete the questionnaire at the site; they were, however, willing to participate if they could take the questionnaires home and return with them the following week. Ultimately, no participants remembered to return the questionnaire, and three subsequent visits to each senior center were required to obtain the completed questionnaires.

Description of the Assessment Tool

The Arthritis Self-Efficacy Scale was designed by Lorig, Chastain, Ung, Shoor, and Holman (1989) at the Stanford Arthritis Center to 
evaluate the effectiveness of their class on arthritis management. The scale measures perceived self-efficacy on three subscales: (a) Pain, (b) Function, and (c) Other Symptoms. The Pain subscale assesses how the arthritis pain affects the respondent through questions regarding the person's ability to control the pain. The Function subscale assesses how confident the respondent is to perform daily activities, such as walking, getting out of a chair, or cutting a piece of meat. The Other Symptoms subscale measures the respondent's ability to control other symptoms of arthritis, such as fatigue and emotions, which might influence his or her ability to perform the activities of daily living.

The questionnaire consisted of 20 questions: 5 questions in the selfefficacy Pain subscale; 9 questions for the self-efficacy Function subscale, and 6 questions in the self-efficacy Other Symptoms subscale. (The questionnaire is located in Appendix F.) The questionnaire was tested extensively for validity and reliability (Lorig, Chastain, Ung, Shoor, \& Holman, 1989). A verbal authorization was obtained from Dr. Lorig to use the scale and to adapt the questionnaire to meet possible functional limitations of the elderly person by doubling the letter size to improve readability. Lorig, Chastain, Ung, Shoor, and Holman (1989) state that "the authors invite others to use the scale and would appreciate being informed of study results" (p. 40). A written authorization can also be found in Appendix C.

The study and tool were approved for use by the Human Subjects Review Board at San Jose State University (Appendix A). 
Analysis Procedures

The data were analyzed using the independent samples t-test, as was originally used in the Lorig, Chastain, Ung, Shoor, and Holman (1989) studies. Since the scores from the Arthritis Self-Efficacy Scale yielded interval data which allowed for analysis of variance on three subscales, the parametric statistic, independent t-test was used for each subscale to identify significant differences, if any, between the group that exercised and the group that did not exercise. An 2!pha level of $\mathrm{p}<.05$ was seen as adequate to prevent Type I or Type II errors, since the outcome was not related to a life-threatening situation. 


\section{Chapter 4}

\section{ANALYSIS AND INTERPRETATION OF THE DATA}

This section provides an analysis and interpretation of the findings in this study using the Arthritis Self-Efficacy Scale (Lorig, Chastain, Ung, Shoor, \& Holman, 1989). The perceived self-efficacy scores of elderly individuals with arthritis were compared to determine if there were any differences between the scores of those who exercised regularly and those who did not. A consensus was reached among 12 people who regularly attended a senior center or an aquatics exercise class to complete the questionnaire. The exercise group $(\underline{n}=6)$ consisted of participants who actively attended one of the exercise classes or who responded, "yes," to the question, "Do you perform exercises to relieve your arthritis discomforts?" The nonexercise group $(\underline{n}=6)$ consisted of individuals who were not active in any of the exercise classes or who answered, "no," to the question, "Do you perform exercises at home to relieve your arthritis discomforts?" This exploratory study utilized a convenience sample of those who volunteered during the 2 days of verbal solicitation.

Analysis of the Data

Data were analyzed using the independent samples t-test. For each question, a mean was calculated for each independent group. From these calculations, a mean was calculated for each group of the subscale and the means compared. The Arthritis Self-Efficacy Scale measures three different factors: pain, function, and other symptoms. The means of the exercise group were compared with those of the nonexercise group. 
Demographic Profile

The age range of all participants was 66 to 92 years (see Table 1). The mean age of all participants was 75.75: the exercise group averaged 71.5 years of age; and the nonexercise group averaged 80.0 years of age. The group consisted of 3 males and 9 females: the exercise group consisted of 1 male and 5 females; the nonexercise group consisted of 2 males and 4 females. The age of participants ranged from 66 to 92 years. In comparing the two groups, those participants who exercised were under 70 years of age, and those participants who did not exercise were over 80 years of age.

Table 1

Mean Age and Gender of Participants by Exercise Group $(\underline{I}=12)$

\begin{tabular}{lccc}
\hline & Mean Age & $\begin{array}{c}\underline{\mathrm{n}} \\
\text { Female }\end{array}$ & $\begin{array}{c}\underline{\mathrm{n}} \\
\text { Male }\end{array}$ \\
\cline { 2 - 4 } Exercise Group & 71.5 yrs. & 5 & 1 \\
Nonexercise Group & 80.0 yrs. & 4 & 2 \\
\hline
\end{tabular}

Seven arthritic complications were listed on the demographic face sheet, and respondents indicated which of the seven complications they had experienced. The seven complications were as follows: (a) difficulty dressing, (b) difficulty cooking, (c) difficulty bathing, (d) difficulty performing housekeeping chores, (e) difficulty sleeping, (f) fatigue, and (g) joint discomfort. Among the exercise group, 5 indicated having joint 
discomfort; 4 had fatigue, difficulty sleeping, and difficulty performing housekeeping chores; and 1 had difficulty with dressing, cooking, and bathing. Data from the nonexercise group revealed that all 6 experienced joint discomfort and fatigue; 1 indicated difficulty sleeping; 4 had difficulty performing housekeeping chores; however, no respondents indicated difficulty with dressing, cooking, or bathing. The main difference between the two groups was that the exercise group experienced a higher frequency of difficulty sleeping, and the nonexercise group experienced a higher frequency of fatigue.

The Arthritis Self-Efficacy Scale consisted of 20 questions, divided into three subscales: (a) Pain, (b) Functions, and (c) Other Symptoms. Responses were recorded on a scale ranging from 10 to 100 , with 10 being very uncertain, 50 as moderately certain, and 100 as very certain. Eleven participants completed all of the questions. One subject did not complete item 5 on the Pain subscale. Also, item 2 of the Pain subscale was not included in the data analysis because a typing error during the reproduction of the questionnaire put "very certain" at both ends of the scale, instead of "very uncertain" at the lower end of the scale, and "very certain" at the higher end of the scale. It was not known if the error influenced the response to the question, "How certain are you that you can continue most of your daily activities?" It was also noted that this item 2 was not specifically pain related in comparison to the other questions in that section. When results of the data analyses were examined, omission of this question did not appear to have had an effect on results. 
On the Pain subscale, the exercise group had a mean of 28 , and the nonexercise group had a mean of 30.3 , resulting in a 1 value of 0.34 and a $\mathrm{g}$ value of $.74(\mathrm{~g}<.05)$, which showed no significance. On the Function subscale, the exercise group had a mean of 76.3 , and the nonexercise group, a mean of 59.2, resulting in a \pm value of 1.42 and a $\mathrm{g}$ value of .19 ( $2<.05)$, also nonsignificant. On the Other Symptoms subscale the exercise group had a mean of 43.4 , and the nonexercise group, a mean of 38.0 , resulting in a $t$ value of 0.79 and a $\mathrm{p}$ value of $0.43(\mathrm{p}<.05)$; again, no significance was noted. These data are displayed in Table 2 . The results of the three t-tests showed no statistically significant differences between the exercise and the nonexercise groups on any of the subscales.

Table 2

Analysis of Perceived Self-Efficacy Scores Between Exercisers and Nonexercisers $(\underline{n}=12)$

\begin{tabular}{|c|c|c|c|c|c|c|}
\hline \multirow[t]{2}{*}{ Subscale } & \multicolumn{2}{|c|}{$\begin{array}{l}\text { Exercise Group } \\
\qquad(\underline{n}=6)\end{array}$} & \multicolumn{2}{|c|}{$\begin{array}{l}\text { Nonexercise Group } \\
\qquad \underline{n}=6)\end{array}$} & \multirow[b]{2}{*}{$\underline{t}$} & \multirow[b]{2}{*}{$\mathrm{P}$} \\
\hline & $\mathrm{M}$ & $S D$ & $\mathrm{M}$ & SD & & \\
\hline Pain & 28.0 & 11.4 & 30.3 & 11.0 & .34 & .74 \\
\hline Function & 76.3 & 15.8 & 59.16 & 24.9 & 1.42 & .19 \\
\hline $\begin{array}{l}\text { Other } \\
\text { Symptoms }\end{array}$ & 43.4 & 8.44 & 38.0 & 13.07 & .79 & .43 \\
\hline
\end{tabular}


Interpretation of the Findings

As noted, there was no statistically significant difference between the two groups on any of the subscales. Therefore, this small population of people who exercised did not demonstrate higher self-efficacy, nor did nonexercisers exhibit less self-efficacy beyond what might be considered a chance occurrence. However, a closer look at responses to the individual questions did reveal a trend among exercisers to report difficulty sleeping. The nonexercise group represented an older population and reported overall lower scores of functional limitations and other symptoms. The nonexercise group also reported a higher occurrence of fatigue and joint discomfort. The Pain subscale scores were almost equivalent.

Difficulty sleeping occurred more frequently among the exercise group and among those who were under 75 years of age. Though fatigue was reported more frequently in the nonexercise group (mean age of 80.0 years), fatigue occurred equally between those under 75 years and those over 80 years. Ioint discomfort occurred more often among those below 75 years in comparison to those individuals over 80 years of age.

Gender-related factors did not show any significance in the analysis. Of the 3 males who participated, 1 male exercised, and 2 did not. All males reported difficulty performing housekeeping chores and joint discomfort; 1 reported difficulty bathing, and 2 reported having fatigue. There was no specific factor related to the frequency of complications and exercise activity. 


\section{Chapter 5}

\section{DISCUSSION AND CONCLUSION}

It was anticipated that elderly individuals with arthritis who exercised would have a higher perceived self-efficacy score than elderly individuals who did not exercise. Bandura (1982) proposed that individuals' judgments of how well they can accomplish specific tasks do have an impact on the success or failure of the execution of that task. The majority of the studies substantiated the importance of self-efficacy when incorporated into therapeutic modalities evident in studies performed by Minor et al. (1989), O'Leary et al. (1988), and Bandura (1982), but other studies (Lenker et al., 1989; Lorig, Chastain, Ung, Shoor, \& Holman, 1989; Schiaffino et al., 1991) have demonstrated that only a weak association exists between improved health behaviors and resulting health outcomes.

\section{Conclusions}

The results of this study are in agreement with the findings of Lenker et al. (1989), Lorig, Seleznick, Lubeck, Ung, Chastain, and Holman (1989), and Schiaffino et al. (1990). Because of the lack of consensus in the literature regarding the role of attitude, further research is needed to explain the reason for different coping behaviors toward the management of disease complications.

The demographic variables showed that both groups experienced similar arthritic complications, with the exception of difficulty sleeping, which was more prevalent among those in the 65-75 year age range and 
the exercise group. Because of expressed sleeping problems, the subjects in the exercise group may be using that activity in an attempt to alleviate this problem.

Exercise was not a significant factor in regard to a higher perceived self-efficacy score. That is, those who exercised did not feel they were any more in control of their symptoms than the nonexercise group. The nonexercise group participants were generally older $(\underline{M}=80)$ than the exercise group $(\underline{M}=71.5)$, and there was an even distribution of reported arthritic complications between both groups (with the exception of difficulty sleeping). Because of their older ages, the nonexercise group participants may be coping with arthritic discomfort in ways other than exercise, such as relaxation techniques or diet. It could be speculated that the older people did not have the energy to exercise. And since these variables were not measured in this study, a need for further research is indicated. What was common to both groups was socialization outside of the home which tended to divert attention from the arthritic discomfort. This outside involvement in itself may be a coping behavior for elderly people who suffer from arthritic complications.

Looking at the individual questions on the three subscales, it was noted that there was a tremendous variety in the range of answers, especially on the Function subscale. It was noted that on the Function subscale the behaviors assessed required a number of different skills-from buttoning clothing to getting out of an armchair without using hands for support. This has different implications for people who have limited fine motor functions in their hands, but can easily walk, and others 
who suffer from arthritic knees or hip changes that interfere with walking, but have no effect on fine motor skills. For example, question number 3 on the Function subscale asks, "As of now, how certain are you that you can get out of an armless chair quickly, without using your hands for support?" Answers ranged from 10, the lowest score, to 100, with an average score of 54.17. Question number 4 on the same subscale asks, "As of now, how certain are you that you can button and unbutton three medium-size buttons in a row in 12 seconds?" This, too, produced scores ranging from 10 to 100 , with an average of 69.16. Appendix G presents raw scores of all participants across all subscales. This lack of differentiation between different kinds of skills could account for the lack of significance between the exercisers and the nonexercisers. Another tool which factors out physical limitation might generate more specific data.

Scope and Limitations

This study is limited by the small number of participants. A larger population could reveal more conclusive evidence regarding perceived self-efficacy among elderly individuals with arthritis. It should be noted that the low participation may have been affected by the time period when the data collection occurred, which was during the holiday season of December, 1992 and January, 1993. Other reasons could be that most had inflexible scheduled transportation after the exercise class or noon meal. The area was also experiencing an unusual amount of rainy weather during the time of data collection, which may have contributed to the low subject participation. Some individuals did show interest but not the patience to wait for further explanation of the questionnaire or completion of the 
consent form. The combination of rainy weather, fear of missing scheduled transportation, and hectic holiday activities may have affected potential individual participation. Most seniors who were approached indicated that they did not have time to complete the study, even though they had the option to take this questionnaire home. Those seniors who did complete the questionnaire required prompting and reminders to return the questionnaires after they were taken home.

Another limitation was that respondents were recruited from only three sites. Other community senior activities, such as the arthritis club and other senior centers, should be utilized for the recruitment of additional respondents. The investigator did attempt to obtain respondents from the arthritis club, but because no meeting was held during December, when the bulk of data collection occurred, an alternate site was selected.

The method of selection was another limitation. The results were time consuming. Questionnaires could be mailed to people with arthritis, targeted at arthritis club meetings. As for the senior centers, subjects could have been obtained through other means, such as the distribution of flyers.

The scope of the study was limited by age of the population (over 65 years of age) and the fact that participants were required to have had a diagnosis of arthritis for at least 1 year. The inclusion of people of all age groups who suffered from arthritic complications may have provided more conclusive data regarding coping behaviors.

While the tool was subjected to a number of reliability and validity tests by its original authors, it had been used only with persons involved 
in the Lorig Arthritis Self-Management Program and, therefore, may not be as useful for a different population. Also, there was no differentiation between persons with osteoarthritis and those with rheumatoid arthritis, a factor which could have an effect on the types of functional limitations experienced by the participants.

\section{Recommendations}

A minimum of 30 participants should be recruited to provide more conclusive data. Data should be collected over a longer period of time to ensure greater participation, and holidays should be avoided.

The inclusion of other variables, such as cultural and ethnic influences, variations in age and education, and comparison of homebound versus nonhomebound people, may provide valuable data. The effects of attitude should also be investigated. The literature points to the need for more research of specific behaviors exhibited by people who are coping successfully with arthritis, compared to those with similar complications who are not coping successfully.

Bandura's (1982) concept of seif-efficacy shouid aiso be studied in other chronic disease ailments, such as cancer and cardiovascular disease. Self-efficacy may prove useful in assisting those who are suffering from the pain which is associated with cancer and those who are recovering from a stroke. Those learning pain control techniques can increase chances for a successful outcome if they realize the importance of their own assessment of themselves. Self-efficacy taught in the rehabilitation of stroke victims may increase their confidence to regain some or all of their previous functional abilities. Because the role of the nurse is connected to 
the direct provision and management of the care for people suffering from disease, Orem's (1991) nursing theory of self-care, used in conjunction with Bandura's (1982) theory of self-efficacy, should be studied for its role in assisting people who are suffering from any chronic disease. Orem's theory stresses the nurse's role in assisting those suffering from disease to achieve their highest potential. Bandura's theory of self-efficacy can be used in implementing therapeutic intervention conducted by nurses, such as educating pain-afflicted individuals in pain management techniques and assisting stroke patients to regain functional mobility. Because the concepts can be used concurrently, the role of self-efficacy used in conjunction with self-care strategies suggests some challenging areas for future research. 


\section{REFERENCES}


References

Abrams, W. B., \& Berkow, R. (Eds.). (1990). The Merck manual of geriatrics. Rahway, NJ: Merck.

Bandura, A. (1982). Self-efficacy mechanism in human agency. American Psychologist, 2, 122-147.

Bandura A., \& Schunk, D. H. (1981). Cultivating competence, selfefficacy, and intrinsic interest through proximal self-motivation. Journal of Personality and Social Psychology, 41, 586-598.

Beck, A. T. (1976). Cognitive therapy and the emotional disorders. New York: International Universities Press.

Fordyce, W. E. (1978). Learning processes in pain. In R. A. Sternbach (Ed.), The psychology of pain (pp. 49-72). New York: Raven Press.

Herman, E., \& Baptiste, S. (1990). Group therapy: A cognitive behavioral model. In E. Tunks, A. Bellissimo, \& R. Ranjan (Eds),, Chronic pain: Psychological factors in rehabilitation (pp. 212-228). Malbar, FL: Robert E. Publishing.

Lenker, S., Lorig, K., \& Gallagher, D. (1989). Reasons for the lack of association between changes in health behavior and improved health status: An exploratory study. Patient Education and Counseling, $\underline{6}$, 69 72.

Lesage, J., Slimmer, L. W., Lopez, M., \& Ellen, J. R. (1989). Learned helplessness. Journal of Gerontologic Nursing, 15, 9-15.

Liang, M. H. (1992, April). Harvard health letter. MA: Harvard Medical School, Harvard University.

Lorig, K., Chastain, E. U., Shoor, S., \& Holman, H. R. (1989). Development and evaluation of a scale to measure perceived selfefficacy in people with arthritis. Arthritis and Rheumatism, 32, 27-44. 
Lorig, K., \& Fries, J. F. (1986). The arthritis handbook. Reading, MA: Addison-Wesley.

Lorig, K., \& Holman, R. H. (1989). Long-term outcomes of an arthritis self-management study: Effects of reinforcement efforts. Social Science Medicine, 20, 221-224.

Lorig, K., Seleznick, M., Lubeck, D., Ung, E., Chastain, R. L., \& Holman, H. R. (1989). The beneficial outcomes of the arthritis selfmanagement course are not adequately explained by behavior change. Arthritis and rheumatism, $\underline{32}, 91-95$.

Marino, C., \& McDonald, E. (1991). Osteoarthritis and rheumatoid arthritis in elderly patients. Arthritis, 90, 237-243.

McIlwain, H. H., Silverfield, J. C., Burnette, M. C., \& Bruce, D. F. (1991). Winning with arthritis. Toronto: John Wiley \& Sons.

McLeod, B. (1986). Prescription for health: A dose of self-confidence. Psychology Today, 46-50.

Minor, M. A. Hewett, J. E., Webel, R. R., Anderson, S. K., \& Kay, D. R. (1989). Efficacy of physical conditioning exercise in patients with rheumatoid arthritis and osteoarthritis. Arthritis and Rheumatism, $\underline{32}$, 1396-1405.

O'Leary, A., Shoor, S., Lorig, K., \& Holman, H. R. (1988). A cognitivebehavioral treatment for rheumatoid arthritis. Health Psychology, $\underline{7}$, 527-544.

Orem, D. E. (1991). Nursing: Concepts of practice (4th ed.). St. Louis: Mosby Year Book. 
Pearce, T., \& Tunks, E. (1990). Multimodal treatment for chronic pain.

In E. Tunks, A. Bellissimo, \& R. Ranjan (Eds). Chronic pain:

Psychosocial factors in rehabilitation (pp. 255-270). Malabar, FL:

Robert E. Publishing Company.

Pisetsky, D. S., \& Trien, S. F. (1991. The Duke University Medical

Center book of arthritis. New York: Fawcett Columbine.

Price, S. A., \& Wilson, L. M.. (1986). Pathophysiology clinical concepts of disease processes (3rd ed.). New York: McGraw-Hill.

Prkachin; K. M., \& Cameron, R. (1990). Behavior and cognitive therapies. In E. Tunks, A. Bellissimo, \& R. Ranjan (Eds.). Chronic pain: Psychosocial factors in rehabilitation (pp. 144-183). Malabar, FL: Robert E. Publishing.

Schiaffino, K. M., Revenson, T. A., \& Gibofsky, A. (1991). Assessing the impact of self-efficacy beliefs on adaption to rheumatoid arthritis. Arthritis Care and Research, 4, 150-157.

Smith, C. A., Dobbins, C. J., \& Wallston, K. A. (1991). The mediational role of perceived competence in psychological adjustment to rheumatoid arthritis. Journal of Applied Social Psychology, 21, 1218-1247.

Stefl, B. M. (1984). Handbook of gerontological nursing. New York: Van Nostrand Reinhold.

Tunks, E. (1990). Psychiatric management of chronic pain. In E. Tunks, A. Bellissimo, \& R. Ranjan (Eds.), Chronic pain: Psychosocial factors in rehabilitation (pp. 229-254). Malabar, FL: Robert E. Publishing. Violon, A. (1990). The process in becoming a chronic pain patient. In E. Tunks, A. Bellissimo, \& R. Ranjan (Eds.), Chronic pain: Psychosocial factors in rehabilitation (pp. 21-36). Malabar, FL: Robert E. Publishing. 
APPENDIX A

Human Subjects Approval Letter 


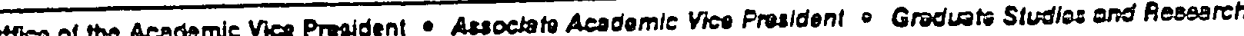

Ona snington Square - San José. Califomis 95192-0025 - 408/924-2480

Ore Whanington Square

To: Elbina Rafizadeh

536 Dufour St.

Santa Cruz, CA 95060

From: serena w. stanford Werene. He ftenfore
AAVP, Graduate studies and Research

Date: November 5, 1992

The Human Subjects-Institutional Review Board has approved your request to use human subjects in the study entitled:

"A study to find a difference in perceived self-

efficacy between elderly individual with Arthritis

who exercise and those who do not exercise"

This approval is contingent upon the subjects participating in your research project being appropriately protected from risk. This includes the protection of the anonymity of the subjects' identity when they paricipate in your research project, and with regard to any and all data that may be collected from the subjects. The Board's approval includes continued monitoring of your research by the Board to assure that the subjects are being adequately and properly protected from such risks. If at any time a subject becomes injured or complains of injury, you must notify Dr. Sereria stanford immediacely. Injury includes but is not limited to bodlly harm, psychological trauma and release of potentially damaging personal information.

Please also be advised that each subject needs to be fully informed and aware that their participation in your research project is voluntary, and that he or she may withdraw from the project at any time. Further, a subject's participation, refusal to participate or withdrawal will not affect any services the subject is receiving or will receive at the institution in which the research is being conducted.

If you have questions, please contact me at 408-924-2480.

cC: Marcia Canton 


\section{APPENDIX B}

\section{Participation Consent Form}




\section{AGREEMENT TO PARTICIPATE IN RESEARCH}

\section{RESPONSIBLE}

INVESTIGATOR(S): ELBINA B.RAFIZAREK PAN
Title of Protocol:

1. I have been asked to participate in a research study investigating the difference in self-efficacy scores between elderly individuals who exercise and elderly individuals who do not.

2. I will agree to answer a self-administered questionnaire titled, Arthritis Self-Efficacy Scale.

3. I understand that there are no foreseeable risks or discomfort.

4. I understand that there are no discernible benefits.

5. I understand that the results of the study may be published but the identity of all participants will be kept confidential.

6. If I have any questions in regards to the research, I can contact Elbina Rafizadeh at (408) 426-1908. Should there be any complaints, I can direct my complaints to Dr. Bobbye Gorenberg, Graduate Coordinator, Nursing Department at San Jose State University at (408) 924-3234. I can also direct my complaints or questions to Serena Stanford, Ph.D., Associate Vice President of Graduate Studies and Research, at (408) 924-2480.

7. I understand that no service entitlements will be jeopardized should I decide to not participate in the study.

8. I understand that my consent to participate in the study is voluntary and may refuse to participate in the study or in any part of the study. I may withdraw at any time withoul prejudice in 
relations with San Jose State University or any other participating institutions.

9. I will be given a signed and dated copy of the consent form.

The signature of a subject on this document indicates agreement to participate in the study.

The signature of a researcher on this document indicates agreement to include the above named subject in the research and attestation that the subject has been fully informed of his or her rights.

Subject's Signature Date


APPENDLX C

Authorization to Use Questionnaire 
SIANFORD ARTIRITIS CENER

Stanford Universthy school of Medicine

Potient Education Research

1000 Welch Rood. Suite 204

Palo Atto. Californio 94304.1808

415/723-7935

$415 / 723-9656$ FAX

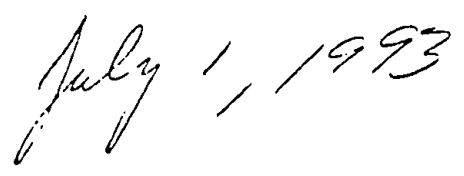

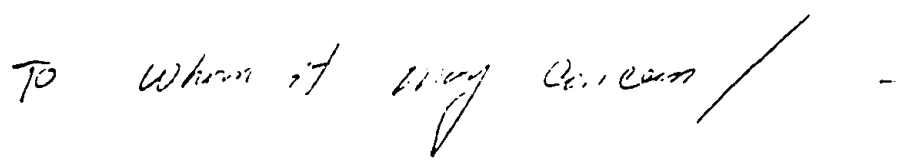

$A=$ stated ir on pintilintion tar

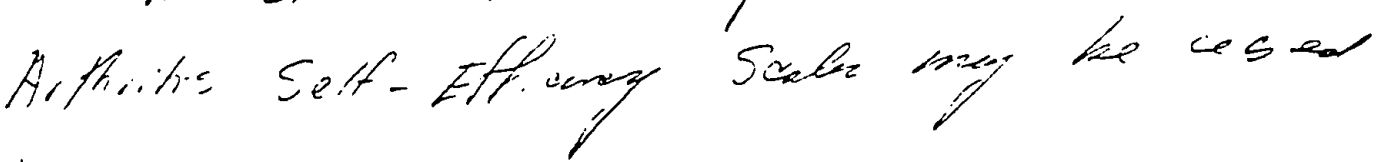

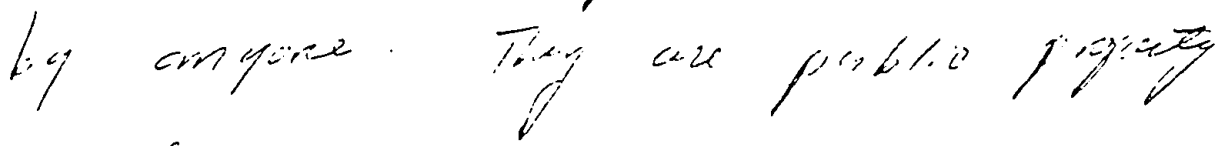

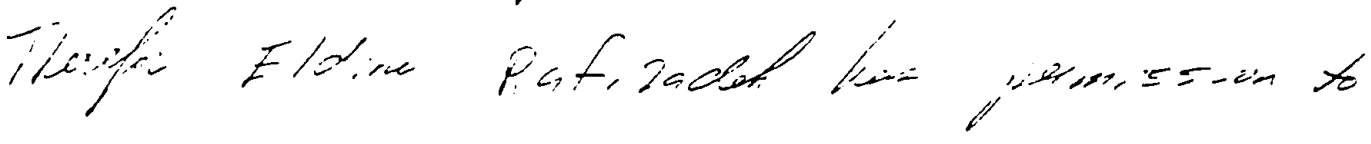

is se fir

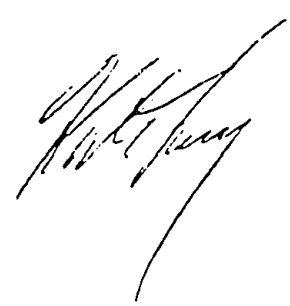


APPENDIX D

Agency Consent Letters 
Wotsoriville Senior Center

114 E. Fifth St.

Hotsonille, CA

September 14, 1992

Eltina Ei Rafizadein

536 Dufour St.

Sonto Cruz, CA 95060

Dear Ms. Fiafizadeh.

This is a letter of cansent which allows you to pursue potentiol individuals agreeatile to participate in your thesis project regarding srihritis poin, for Son Jose stste University. Trie survel involves willing fsticipents to onswer a written questionsire, The arthritis Self-Efitosgy scele.

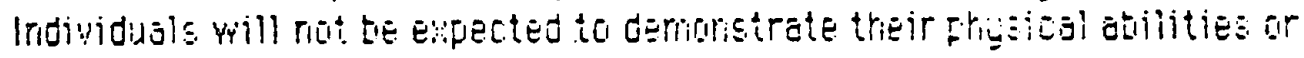
limitgtions. I understard thot esoh indidids will sigr s sescrete consont. form priar to perticipetion.

Verị truly yours,

Eorborg [isis

Executive girector 
City of Sonts Cruz F'orks \& Recrestion

Louder Nelson Center

301 Center Streat

Sento Cruz, CA 95060

Septemitier 8, 1992

Elbina Rafizadeh

530 Duiour St.

Sants CrLiz, CA 95000

Dear ME Rafizadeh,

This is a letter oi consent which ellows you to pursue potential individuals agreeatie to participste in your thesis project for Sari Jose State. Liniversity. I understarid thet the study is a survey involwing ariswering a writier quesiunrierre, stied, Arthritis Self-Eficacy Scole. To minimize and riske irivolyed, individuse should not be espected to demonetrate their physical atilities ar limitistions ard a time limit be placed for the length o: the interview to evold tring oif the irididual. I also uriderstond that escri individual will sign a separate consent iorm prior to porticipsting in the project.

very truly grours,

Lourg Scribner

Senior Citizens Frogrem Euperviscr. 
Fleming 11

Physicsl Therspy

548 Ocean St.

Sonto Cruz, Co. 95050

September 14,1992

Eibina Rafizadeh

536 Dufour St.

Sonto Cruz, CA 95000

Dear Ms. Rofizadeh,

This is 8 letter of consent which allows you to pursue potentisl individusis 8greegtele to participate in your thesis project regarding arthritis pain, for son Jase State University. As explained to me the study is a survey involuing answering a writter questionnare, titled, arthritis Seli-Ejil[ard Eigle. The interview will be conducted at a time agreed unan with the willirig porticipont. To minimize riske, individusls should not be expected to demonstrate their phtesical atilities or limitetions. I understend thet each individusl will sign a seporste consent furm prior to participatian.

Very truly yours,

Lise kroll

Activities Director

Fieming 11 
APPENDIX E

Demographic Face Sheet 


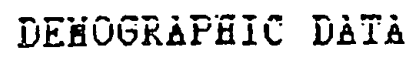

$\triangle G E$

HALE

FEXBLE

BAFE YOU HAD A DIAGNOSIS OF ARTBRITIS FOR LT LEAST ONE YEAR

IES

NO

PLEASE INDICATE IHICH OF TBE COHPLICATIONS OF BRTHRITIS LISTED BELOY YOU ARE CURRENTLI EXPERIENC ING.

Difficulty dressing

Difficulty cooking

Difficulty bathing

Difficulty to perform housekeeping chores

Difficulty sleeping

Fatigue

Joint discomfort

Site number:

Participant number: 
APPENDIX $F$

Arthritis Self-Efficacy Scale 
Arthritis Self-Efficacy Scale

Seli efficacy pain subscale

In the following questions, de'd like to know ho your arthritis pain affects you. For each of the folloving questions, please circle the number vich corresponds to your certainty that you can nor perform the folloging tasks.

1. How certain are you that you can decrease your pain quite a bit?

\begin{tabular}{lllllllll}
\hline $10 \quad 20$ & 30 & 40 & 50 & $\begin{array}{l}60 \\
\text { moderately } \\
\text { certain }\end{array}$ & 90 & 90 & 100 \\
uncertain & & & $\begin{array}{l}\text { cerg } \\
\text { certain }\end{array}$
\end{tabular}

2. Hoy certain are you that you can continue most of your dailg activities?

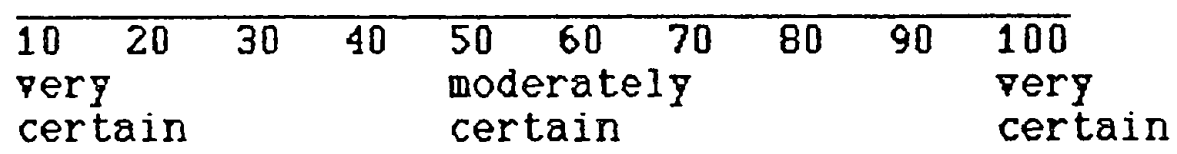

3. How certain are you that you can keep arthritis pain from interfering vith your sleep?

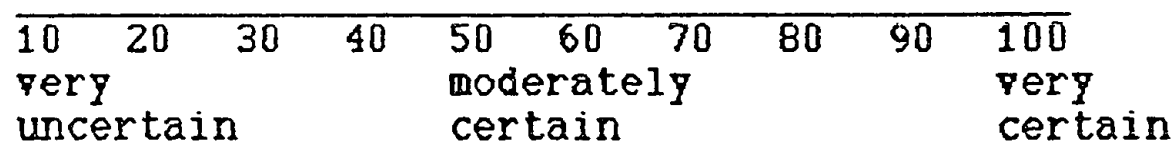

4. Hor certain are you that you can make a small to moderate reduction in your arthritis pain by using methods other than taking extra medication?

\begin{tabular}{llllllll}
\hline $10 \quad 20$ & 30 & 40 & $50 \quad 60$ & 70 & 80 & 90 & 100 \\
$\begin{array}{l}\text { very } \\
\text { uncertain }\end{array}$ & $\begin{array}{l}\text { moderately } \\
\text { certain }\end{array}$ & & & & yerg \\
certain
\end{tabular}


5. Hoy certain are that gou can make a large reduction in gour arthritis pain by using methods other than taking extra medication?

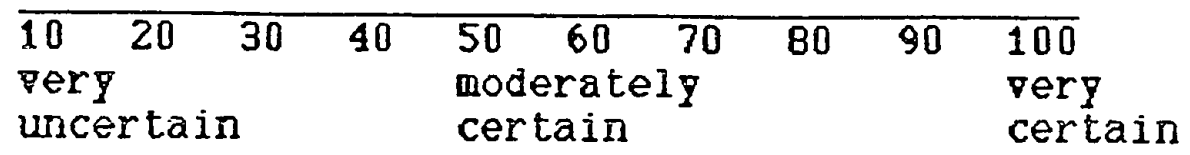

Self-efficacy function subscale

Te ould like to kno ho confident you are in performing certain daily activities. For each of the folloging questions, please circle the number vhich corresponds to your certainty that you can perform the tasks as of nop, rithout assistive devices or help from another person. Please consider vhat you routinely can do, not hat yould require a single extraordinary effort.

AS OF NOR, BOR CERTAIN ARE YOU THaT YOU CAN:

1. Palk 100 feet on flat ground in 20 seconds?

\begin{tabular}{lllllllll}
\hline $10 \quad 20$ & 30 & 40 & $50 \quad 60 \quad 70$ & 80 & 90 & 100 \\
very & $\begin{array}{l}\text { moderatel } \\
\text { certain }\end{array}$ & & & & very \\
uncertain & & & & & certain
\end{tabular}

2. Valk 10 steps dornstairs in 7 seconds?

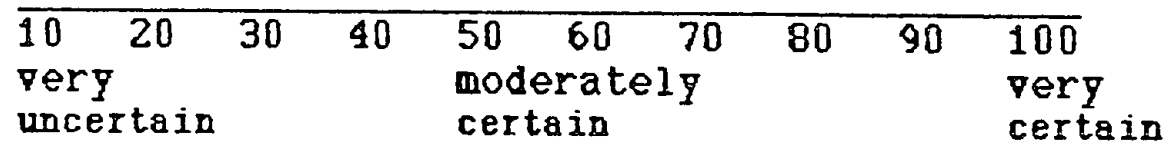

3. Get out of an armless chair quickly, yithout using your hands for support?

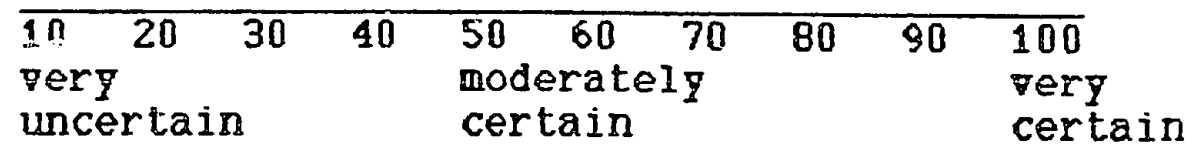

4. Button and unbutton 3 medium-size buttons in a roz in 12 seconds?

\begin{tabular}{lllllllll}
\hline $10 \quad 20$ & 30 & 40 & $50 \quad 60$ & 70 & 80 & 90 & 100 \\
very & & moderately & & & very \\
uncertain & & certain & & & certain
\end{tabular}


5. Cut 2 bite-size pieces of meat 8 ith a knife and fork in 8 seconds?

\begin{tabular}{llllllll}
\hline $10 \quad 20$ & 30 & 40 & $50 \quad 60 \quad 70$ & 80 & 90 & 100 \\
$\begin{array}{l}\text { yery } \\
\text { uncertain }\end{array}$ & $\begin{array}{l}\text { certain } \\
\text { certa }\end{array}$ & & & $\begin{array}{l}\text { pery } \\
\text { certain }\end{array}$
\end{tabular}

6. Turn an outdoor faucet all the ray on and all the vay off?

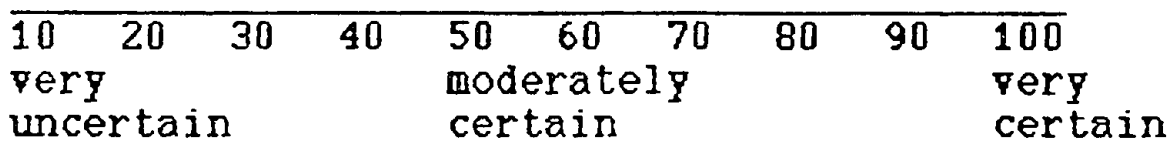

7. Scratch your upper back with both your right and left hands?

\begin{tabular}{llllllll}
\hline $10 \quad 20$ & 30 & 40 & $\begin{array}{l}50 \\
\text { moderately } \\
\text { very } \\
\text { uncertain }\end{array}$ & $\begin{array}{l}\text { certain } \\
\text { uncertan }\end{array}$ & & 90 & $\begin{array}{l}100 \\
\text { very } \\
\text { certain }\end{array}$
\end{tabular}

8. Get in and out of the passenger side of a car vithout assistance from another person and githout physical aids?

\begin{tabular}{lllllllll}
\hline $10 \quad 20$ & 30 & 40 & $\begin{array}{l}50 \\
\text { moderately } \\
\text { very } \\
\text { cerain }\end{array}$ & 80 & 90 & 100 \\
uncertain & & & & $\begin{array}{l}\text { pery } \\
\text { certain }\end{array}$
\end{tabular}

9. Put on a long-sleeve front-opening shirt or blouse (iithout buttoning) in 8 seconds?

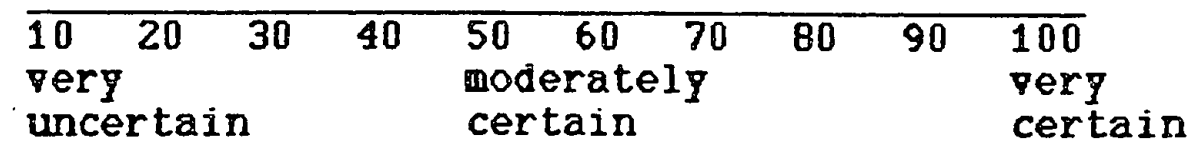

Self-efficacy other symptoms subscale In the folloring questions, ge'd like to knog how you feel about your ability to control your arthritis. For each of the following questions, please circle the number Ehich corresponids to the certainty that you can nog perform the following activities or tasks. 
1. Hor certain are you that you can control your fatigue?

\begin{tabular}{llllllll}
\hline $10 \quad 20$ & 30 & 40 & $50 \quad 60 \quad 70$ & 80 & 90 & 100 \\
very & $\begin{array}{l}\text { moderately } \\
\text { certain }\end{array}$ & & & & very \\
uncertain & & & & &
\end{tabular}

2. Hor certain are you that you can regulate your activity so as to be active yithout aggravating your arthritis?

\begin{tabular}{|c|c|c|}
\hline $\begin{array}{l}10 \quad 20 \quad 30 \quad 40 \\
\text { very } \\
\text { uncertain }\end{array}$ & $\begin{array}{l}50 \quad 60 \quad 70 \\
\text { moderately } \\
\text { certain }\end{array}$ & \\
\hline
\end{tabular}

3. Ho certain are you that you can do something to help pourself feel better if you are feeling blue?

\begin{tabular}{llllllll}
\hline $10 \quad 20$ & 30 & 40 & $\begin{array}{l}50 \quad 60 \quad 70 \\
\text { moderately } \\
\text { certain }\end{array}$ & 80 & 90 & 100 \\
uncertain & & & & $\begin{array}{l}\text { verg } \\
\text { certain }\end{array}$
\end{tabular}

4. As compared vith other people vith arthritis like yours, ho certain are you that you can manage arthritis pain during your dailg activities?

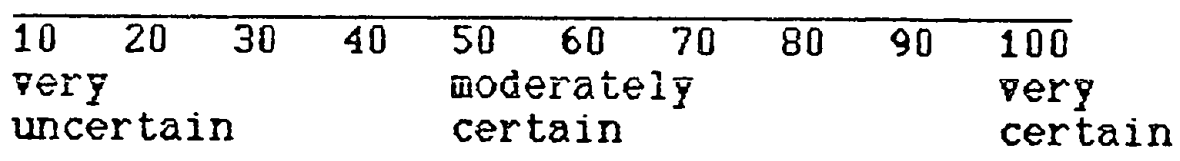

5. Hor certain are you that you can manage your arthritis so that you can do the things you enjoy doing?

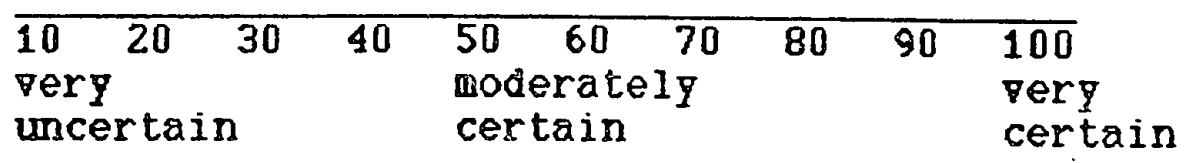

6. Ho certain are you that you can deal with the frustration of arthritis?

\begin{tabular}{lllllllll}
\hline $10 \quad 20$ & 30 & 40 & 50 & 60 & 70 & 80 & 90 & 100 \\
very & $\begin{array}{l}\text { moderately } \\
\text { certain }\end{array}$ & & & pery \\
uncertain & & & & & certain
\end{tabular}


APPENDIX G

Raw Data Scale 


\begin{tabular}{|c|c|c|c|}
\hline D & ㅁำ? & 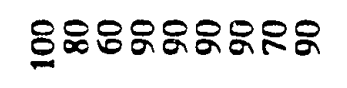 & RঃR৪ \\
\hline 莒 & ஓฌঃ৫ & 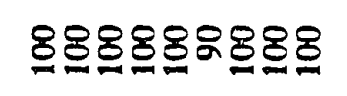 & タタะタタタ \\
\hline 禺 & RRRR & 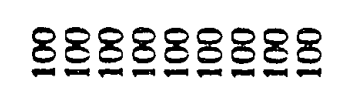 & ㅇRRㅛㅁㅇㅛ \\
\hline$\widetilde{\Sigma}$ & 8888 & タะสิกำดดอด & ORRRER \\
\hline 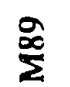 & 유ㅌㅠㅠㅠ & 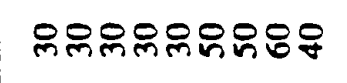 & 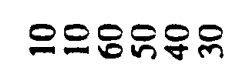 \\
\hline$\frac{\infty}{\Sigma}$ & 조ำำ은 & 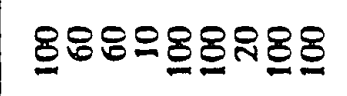 & 8유묭요 \\
\hline 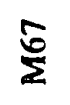 & 윰으유묘 & 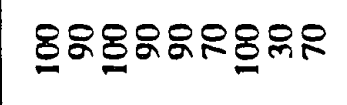 & R\&NRRন \\
\hline$\vec{\infty}$ & RDE. & 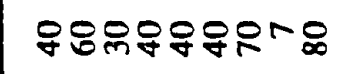 & RRRBRE \\
\hline 号 & 8888 & 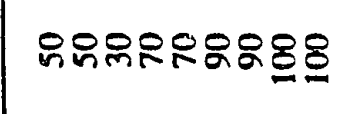 & ஃะ8ะ8๐ \\
\hline$\hat{\sigma}$ & 윰요욤 & 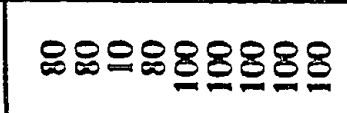 & 윰요ำin \\
\hline$\tilde{E}$ & 유아 & 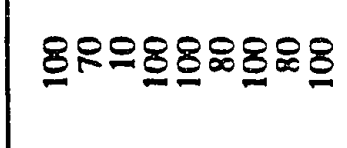 & \%ะ융ㅇㅇ용 \\
\hline$\stackrel{8}{0}$ & $\begin{array}{l}\text { 8888: } \\
\text {-imivivi }\end{array}$ & 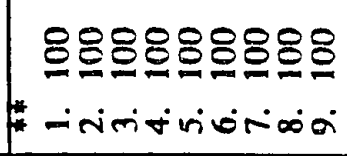 & * \\
\hline
\end{tabular}

